Article

\title{
Mucoadhesive Interpolyelectrolyte Complexes for the Buccal Delivery of Clobetasol
}

\author{
Venera R. Garipova ${ }^{1}$, Chiara G. M. Gennari ${ }^{2}$, Francesca Selmin ${ }^{2}$, Francesco Cilurzo ${ }^{2}$ (1) and \\ Rouslan I. Moustafine ${ }^{1, *}$ \\ 1 Department of Pharmaceutical, Analytical and Toxicological Chemistry, Kazan State Medical University, \\ 49 Butlerov Street, 420012 Kazan, Russia; venero4ka_87@mail.ru (V.R.G.) \\ 2 Department of Pharmaceutical Science, University of Milan, Via G. Colombo 71, 20133 Milan, Italy; \\ chiara.gennari@unimi.it (C.G.M.G.); francesca.selmin@unimi.it (F.S.); francesco.cilurzo@unimi.it (F.C.) \\ * Correspondence: ruslan.mustafin@kazangmu.ru; Tel.: +7-843-252-1642
}

Received: 28 November 2017; Accepted: 8 January 2018; Published: 17 January 2018

\begin{abstract}
This work aimed to investigate the feasibility to design: (a) a mucoadhesive interpolyelectrolyte complex (IPEC) loaded with clobetasol propionate (CP) intended to treat oral lichen planus and (b) individuate an orodispersible dosage form suitable for its administration. IPECs were synthesized by mixing Eudragit ${ }^{\circledR}$ E PO (EPO) and different grades of cross-linked polyacrylate derivatives, in different molar ratios, namely 1:1, 1:2, and 2:1. All IPECs resulted at nanoscale independently of their composition $(120-200 \mathrm{~nm})$. Both zeta-potentials $(\zeta)$ and mucoadhesive performances were influenced by the ratio between polymers. On the bases of the preliminary data, IPECs made of Polycarbophil and EPO in the 1:2 ratio were loaded with CP. The encapsulation efficiency was up $88 \%$ independently of the CP-IPEC ratio. The drug encapsulation caused IPEC destabilization in water, as it was noticed by the increase of $\zeta$ values and the formation of aggregates. Oral lyophilisates were prepared by freeze-drying slurries made of placebo or CP loaded IPECs, maltodextrin with a dextrose equivalent 38 and Span ${ }^{\circledR} 80$. The optimized formulation permitted to obtain a fast disintegration upon contact with water reducing the tendency of IPECs to aggregate. Moreover, oral lyophilisates allowed improving the apparent solubility of $\mathrm{CP}$ throughout the in vitro release experiment.
\end{abstract}

Keywords: Carbopol; clobetasol; Eudragit ${ }^{\circledR}$ E PO; interpolyelectrolyte complex; mucoadhesion; oral lichen planus; oral lyophilisates; maltodextrin; resuspendibility

\section{Introduction}

Interpolyelectrolyte complexes (IPECs) are formed in aqueous dispersions by spontaneous association of oppositely charged polyelectrolytes due to strong but reversible electrostatic interactions [1]. The mild preparation procedure and responsiveness to various stimuli (i.e., $\mathrm{pH}$, temperature, and osmolarity) without cross-linking agents or auxiliary molecules, e.g., catalysts, thereby reducing possible toxicity and other undesirable effects of the reagents. As the obtained polymeric networks are biocompatible and well-tolerated, they are exploited in drug delivery to administer both small drugs [2] and peptides or proteins by several routes, e.g., ocular [3], nasal [4], and oral [5].

Depending on the main features of selected polymers, IPECs exhibit peculiar physico-chemical properties due to their electrostatic interactions and flexibility. For instance, upon mixing two aqueous solutions of oppositely charged polyelectrolytes in a stoichiometric ratio, the resulting IPEC is insoluble and precipitates out [6], often as a colloid [7]. Then, the definition of a suitable drying technique, and the relative protocol, is required to improve their physical and microbiological stability. However, 
drying could also cause the formation of irreversible aggregates of irregular shape and size considering the IPEC dimensions.

Recently, a type of IPEC constituted by a poly(amino methacrylate) and an anionic polyacrylate derivative was proposed as mucoadhesive microparticles [8] which could be exploited in the treatment of buccal pathologies since it prolongs the residence time on a wide surface area. In contrast, the design of a suitable dosage form to administer a powder in the buccal cavity could be problematic in terms of dose accuracy and the easiness in handling. In the attempt to solve these issues, in this work we demonstrated the feasibility to prepare oral lyophilisates [9] containing mucoadhesive IPEC composed of Eudragit ${ }^{\circledR}$ E PO (EPO) and Polycarbophil ${ }^{\circledR}$. This material was chosen among a homogenous series of cross-linked polyacrylate derivatives able to provide the original suspension with unmodified particle size and size distribution, as detailed in Scheme 1. IPECs were loaded with Clobetasol proprionate (CP) selected as a model drug since it is mainstay of topical treatment for oral lichen planus (OLP) [10]. It should be noted that despite many international guidelines refer that its topical application allows good management of this condition reducing systemic side-effects [11], dosage forms intended for buccal route are still not available.

The experimental work was organized in three steps, as detailed in Scheme 1, which summarizesthe the selection criteria and the most important variables to be considered. Firstly, placebo IPECs made of EPO and four different types of carbomers were produced to elucidate the effect of the polycomplex composition on mucoadhesive properties and physico-chemical features. IPECs with satisfactory mucoadhesive properties were loaded with different amounts of $\mathrm{CP}$ to investigate the maximum loading ability of IPECs. Secondly, placebo and CP loaded IPECs were formulated as oral lyophisates using maltodextrin as main matrix forming materials due to its excellent water solubility [12]. Finally, considering the low aqueous solubility of CP $(\sim 4 \mathrm{mg} / \mathrm{mL})$ [13], the possibility to improve the drug apparent solubility was also investigated.

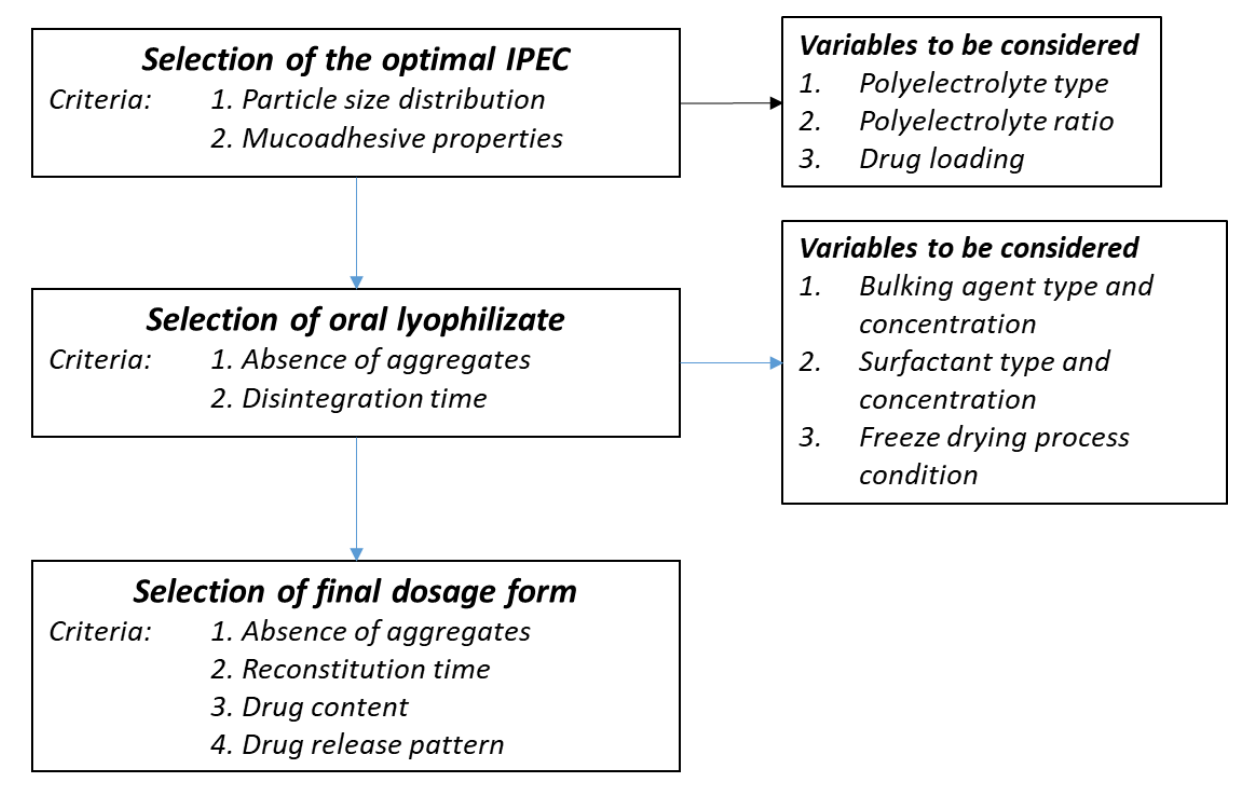

Scheme 1. Technological steps of preparing oral lyophilisates containing IPECs.

\section{Materials and Methods}

\subsection{Materials}

Eudragit ${ }^{\circledR}$ E PO (EPO) - a terpolymer of $N, N$-dimethylaminoethyl methacrylate (DMAEMA) with methylmethacrylate (MMA) and butylmethacrylate (BuMA), (PDMAEMA-co-MMA-co-BuMA) (mole ratio 2:1:1, MW $150 \mathrm{kDa}$ ) was used in this study as a cationic copolymer. Different grades 
of carbomer derivatives (Carbopol ${ }^{\circledR} 71 \mathrm{G}$ NF polymer (C71G), Carbopol ${ }^{\circledR}$ ETD 2020 NF polymer (C2020), Carbopol ${ }^{\circledR}$ Ultrez 10 NF polymer (C10) and Noveon ${ }^{\circledR}$ AA-1 Polycarbophil USP (NAA-1)) were used as polyanions. EPO and different types of Carbopol ${ }^{\circledR}$ (C71G, C2020, C10) as well as Noveon ${ }^{\circledR}$ AA-1 (NAA-1) were generously donated by Evonik Röhm GmbH (Darmstadt, Germany) and Lubrizol Advanced Materials (Wickliffe, OH, USA), respectively. Their main relevant physicochemical characteristics as specified by manufacturers are summarized in Table 1. The polymers were used after drying at $40{ }^{\circ} \mathrm{C}$ under vacuum over a 2 day-period. Maltodextrin with a dextrose equivalent 38 (Glucidex IT38, DS) was kindly gifted by Roquette (Lestrem, France). Span ${ }^{\circledR} 80$ and Tween ${ }^{\circledR} 80$ were provided by Croda Lubricants (Snaith, UK) and Carlo Erba Reagenti, (Milan, Italy), respectively. Clobetasol 17-propionate (CP) was purchased from SICOR (Pero, Italy). All solvents were of analytical grade, unless specified.

Table 1. Physicochemical characteristics as specified by Evonik (healthcare.evonik.com) for Eudragit ${ }^{\circledR}$ E PO (EPO) and Lubrizol Advanced Materials (lubrizol.com) for polycarbophil and different grades of carbomer used to prepare interpolyelectrolyte complex (IPEC). (Abbreviation: Monomers: AA—acrylic acid; EG—ethylene glycol; PAA—polyacrylic acid; crosslinking agents: AEPE—allyl ester of pentaerythritol; DVG-divinyl glycol).

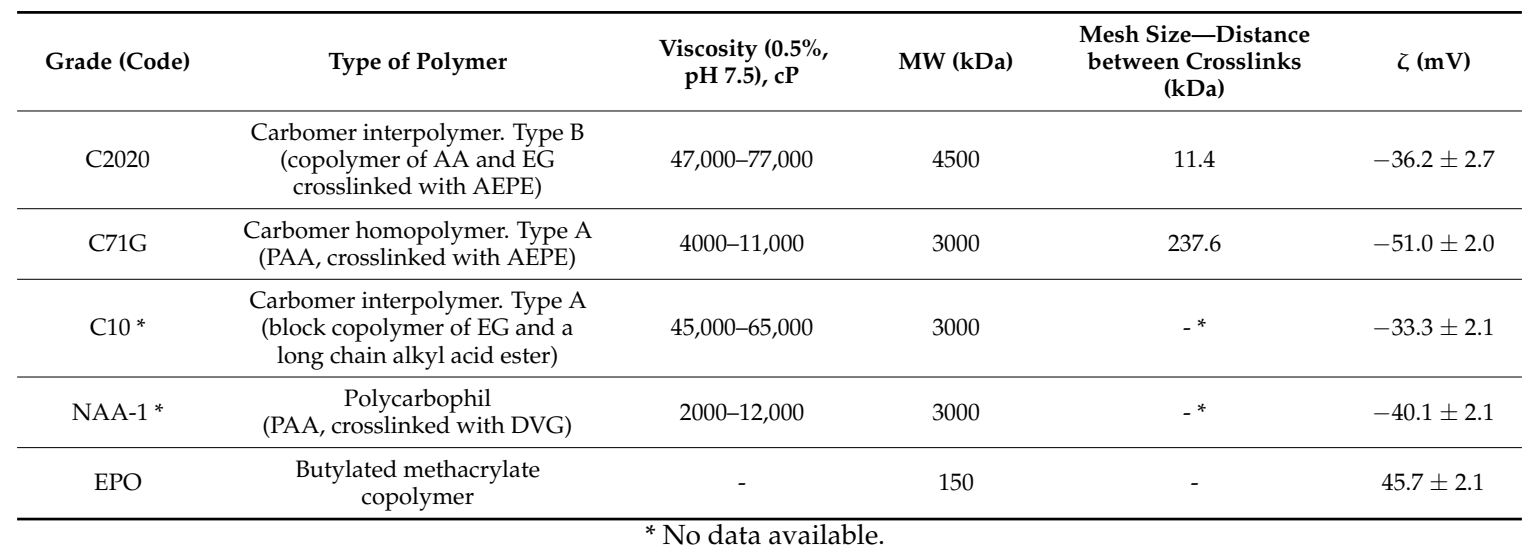

\subsection{Synthesis of Placebo and CP Loaded IPECS}

The conditions to optimize the interaction between chemically complementary grades of a polycationic (EPO) and a polyanionic (C71G, C2020, C10, NAA-1) polymer in the presence of CP were evaluated in an aqueous medium. EPO solution was obtained dissolving EPO in $1 \mathrm{M} \mathrm{CH}_{3} \mathrm{COOH}$. Then, it was diluted with deionized water to the required volume and the $\mathrm{pH}$ was adjusted to 7.0 with $1 \mathrm{M}$ $\mathrm{NaOH}$. Carbomer dispersions were prepared by dispersing and swelling the polymer in $1 \mathrm{M} \mathrm{NaOH}$. This dispersion was diluted with demineralized water to the desired volume and the $\mathrm{pH}$ was adjusted to 7.0 with $1 \mathrm{M} \mathrm{CH}_{3} \mathrm{COOH}$. The EPO solutions were slowly poured into carbomer-CP dispersions [10]. The solutions and dispersions of copolymers and $\mathrm{CP}$ were mixed in different IPEC-CP weight ratios (e.g., 90:10, 80:20, 70:30, 60:40, 50:50 w/w), using three Carbomer/EPO ratios in synthesized IPECs (in equal quantities and with an excess of EPO or Carbopol ${ }^{\circledR}$ ).

The optimal composition of IPEC (placebo) and IPEC-CP systems were obtained in a reactor system LR 1000 control equipped with $\mathrm{pH}$ - and temperature controlling units (IKA ${ }^{\circledR}$, Staufen, Germany) under continuous agitation using overhead stirrer Eurostar 60 control (IKA ${ }^{\circledR}$, Staufen, Germany) at $500 \mathrm{rpm}$. The feeding rate of EPO solution was about $2 \mathrm{~mL} / \mathrm{min}$ and mixtures were stirred over a 7 day period. After the isolation, IPEC-CP particles were washed with ultrapure water (Smart2Pure UV/UF, Thermo Fisher Scientific, Waltham, MA, USA) and subsequently dried under vacuum at $40^{\circ} \mathrm{C}$ (vacuum oven VD 23, Binder, Germany) over a 2 day period until constant weight. The samples were stored in tightly sealed containers at room temperature until use. The elementary analysis on placebo 
IPEC samples was carried out by a Thermo Flash 2000 CHNS/O elemental analyzer (Thermo Fisher Scientific, Paisley, UK).

\subsection{IPEC Characterization}

\subsubsection{Dynamic Light Scattering}

To determine the hydrodynamic diameter $\left(D_{\mathrm{h}}\right)$ of IPECs, laser diffraction analysis was carried out using a Zetasizer Nano ZS (Malvern Instruments, Worcestershire, UK). This technology determines particle sizes in the range from $0.5 \mathrm{~nm}$ to $5 \mu \mathrm{m}$ allowing the detection of particle aggregates in a suspension. Since the particle stability was not sufficient in pure water during a single measurement, Span ${ }^{\circledR} 80$ at the concentration of $0.25 \%$ was used as a steric stabilizer. The analysis was conducted at a scattering angle of $173^{\circ}$ and a temperature of $25^{\circ} \mathrm{C}$.

\subsubsection{Zeta-Potential Measurements}

Charge was determined as the zeta potential $(\zeta)$ by using folded capillary cell at $25{ }^{\circ} \mathrm{C}$ using a Zetasizer Nano ZS (Malvern Instruments, Worcestershire, UK). The results are reported as mean \pm standard deviation $(n=3)$.

\subsubsection{Modulated DSC Analysis}

Thermal analysis on IPEC, CP, IPEC-CP were carried out using a modulated differential scanning calorimetry (MDSC; Discovery DSC ${ }^{\mathrm{TM}}$, TA Instruments, Newcaste, DE, USA), equipped with a refrigerated cooling system (RCS90, TA Instruments, Newcastle, DE, USA). Samples of about $5 \mathrm{mg}$ exactly weighted were sealed in Tzero aluminium pans (TA Instruments, Newcastle, DE, USA) and empty pan was used as a reference. The mass of the reference and sample pans were considered to normalize the data. Dry nitrogen at a flow rate of $50 \mathrm{~mL} / \mathrm{min}$ was used to purge the DSC cell. Indium and $n$-octadecane standards were used to calibrate the DSC temperature scale; enthalpic response and heat capacity were calibrated with indium and sapphire, respectively. The modulation parameters were set as follows: $2{ }^{\circ} \mathrm{C} / \mathrm{min}$ heating rate, $40 \mathrm{~s}$ period and $1{ }^{\circ} \mathrm{C}$ amplitude. Samples were analyzed from 25 to $250^{\circ} \mathrm{C}$. Glass transition temperature was determined in the reversing heat flow signals by using TRIOS ${ }^{\mathrm{TM}}$ software (version 3.1.5.3696, TA Instruments, Newcastle, DE, USA).

\subsubsection{FTIR-Spectroscopy}

ATR-FTIR-spectra were recorded using a Nicolet iS5 FTIR-spectrometer (Thermo Fisher Scientific, Waltham, MA, USA) equipped with a DTGS detector (Thermo Fisher Scientific, Waltham, MA, USA). IPECs, raw polymers (i.e., C71G, C2020, C10, NAA-1) and vacuum-dried IPEC-CP were directly placed on the iD5 smart single bounce ZnSe ATR crystal. The spectra were analysed using OMNIC spectra software (Thermo Fisher Scientific, Waltham, MA, USA).

\subsection{In Vitro Mucoadhesive Properties of Placebo IPECS}

The texture analysis was performed as previously described [14] using mucin as the adherent substrate [15]. Mucoadhesive properties were determined by using a software-controlled texture analyzer (Instron 5965, Instron, Pianezza, Italy) equipped with a $50 \mathrm{~N}$ force cell in adhesion mode. A flat faced compact of testing materials (weight: $170 \mathrm{mg}$, diameter: $11.28 \mathrm{~mm}$ ) was obtained by applying a compression force of 10 tons for $30 \mathrm{~s}$ by means of a hydraulic press (Glenrothes, UK). Compacts were glued to the mobile steel punch. A mucin compact (weight: $130 \mathrm{mg}$, diameter: $11.28 \mathrm{~mm}$ ) obtained applying a compression force of 10 tons for $60 \mathrm{~s}$, was glued to a steel plate fixed at the bottom of the tensile apparatus. Both compacts were hydrated with $50 \mu \mathrm{L}$ deionized water for 5 min to obtain a jelly layer. Upon making contact between the two hydrated compacts, a constant force of $1.3 \mathrm{~N}$ was applied over $360 \mathrm{~s}$. The mucoadhesive properties were expressed as maximum detachment force (MDF), namely the force required to separate the IPEC compact from mucin upon 
an elongation of $25 \mathrm{~mm}$ at the rate of $0.1 \mathrm{~mm} / \mathrm{s}$; work of adhesion (WA), namely the area under the curve of the detachment force versus the elongation which represents the energy necessary to detach two compacts. Polyethylene plates and chitosan compacts were used as negative and positive control, respectively. The results are expressed as mean \pm standard deviation $(n=4)$.

\subsection{Preparation of Oral Lyophilisates}

To set-up the freeze-drying parameters, the glass transition temperature of the maximally freeze-concentrated phase $\left(T_{\mathrm{g}}{ }^{\prime}\right)$ of the aqueous solution of DS in the presence of different components was determined by a DSC 1 STARe System (Mettler Toledo, Greifensee, Switzerland). In brief, aliquots of about 30-40 mg were cooled below the expected $T_{\mathrm{g}}{ }^{\prime}$ at $1 \mathrm{~K} / \mathrm{min}$ and kept at the temperature for $5 \mathrm{~min}$. Thereafter, samples were re-heated at $5 \mathrm{~K} / \mathrm{min}$ to room temperature. To optimize the tablet formulation, the effect of DS concentration and the presence of a surfactant (Span ${ }^{\circledR} 80$ or Tween ${ }^{\circledR} 80$ ) in different concentrations on the tablet disaggregation time and IPEC size were evaluated. The composition of tablets loaded with placebo IPECs is reported in Table 2.

Table 2. Tablet composition and its influence on hydrodynamic diameter $\left(D_{\mathrm{h}}\right)$ and zeta potential $(\zeta)$ of placebo IPECs after disintegration.

\begin{tabular}{|c|c|c|c|c|c|c|c|c|}
\hline \multirow{2}{*}{$\begin{array}{l}\text { Tablet } \\
\text { Code }\end{array}$} & \multicolumn{5}{|c|}{ Tablet Composition $(\%, w / w)$} & \multirow{2}{*}{$\begin{array}{l}\text { Disintegration } \\
\text { Time (s) }\end{array}$} & \multirow{2}{*}{$D_{\mathrm{h}}(\mathrm{nm})$} & \multirow{2}{*}{$\zeta(\mathrm{mV})$} \\
\hline & IPEC 1 & IPEC 8 & DS & S80 & T80 & & & \\
\hline 1 & $10 \%$ & - & 40.9 & - & - & 6 & $149 \pm 42(54.9 \%)$ & n.d. \\
\hline 2 & $10 \%$ & - & 81.8 & - & - & n.d. * & - & - \\
\hline 3 & - & $10 \%$ & 40.9 & - & - & 11 & $136 \pm 16(95.6 \%)$ & $-26.6 \pm 0.7$ \\
\hline 4 & - & $10 \%$ & 81.8 & - & - & n.d. * & - & - \\
\hline 5 & $10 \%$ & - & 40.9 & 0.01 & - & 20 & $141 \pm 0(97.8 \%)$ & $-26.6 \pm 0.6$ \\
\hline 6 & $10 \%$ & - & 40.9 & 0.1 & - & 6 & $132 \pm 8(90.0 \%)$ & $-25.8 \pm 0.1$ \\
\hline 7 & $10 \%$ & - & 40.9 & 0.5 & - & 26 & $145 \pm 8(98.4 \%)$ & $-26.0 \pm 1.3$ \\
\hline 8 & $10 \%$ & - & 40.9 & - & 0.01 & n.d. $* *$ & - & - \\
\hline 9 & $10 \%$ & - & 40.9 & - & 0.1 & n.d. ** & - & - \\
\hline 10 & $10 \%$ & - & 40.9 & - & 0.5 & n.d. $* *$ & - & - \\
\hline 11 & - & $10 \%$ & 40.9 & 0.01 & - & 33 & $125 \pm 10(100 \%)$ & $-26.3 \pm 1.9$ \\
\hline 12 & - & $10 \%$ & 40.9 & 0.1 & - & 12 & $111 \pm 9(100 \%)$ & $-25.1 \pm 3.0$ \\
\hline 13 & - & $10 \%$ & 40.9 & 0.5 & - & 15 & $114 \pm 12(98.2 \%)$ & $-19.0 \pm 2.1$ \\
\hline 14 & - & $10 \%$ & 40.9 & - & 0.01 & n.d. $* *$ & - & - \\
\hline 15 & - & $10 \%$ & 40.9 & - & 0.1 & n.d. ${ }^{* *}$ & - & - \\
\hline 16 & - & $10 \%$ & 40.9 & - & 0.5 & n.d. $* *$ & - & - \\
\hline 17 & $20 \%$ & - & 40.9 & 0.5 & - & 26 & $165 \pm 1(100 \%)$ & $-46.9 \pm 1.2$ \\
\hline
\end{tabular}

* Tablets presented an irregular surface due to the presence of bubbles. ${ }^{* *}$ Tablets were sticky and, therefore, difficult to handle.

Aliquots of $200 \mu \mathrm{L}$ were poured into the cavity of PVC/OPA/Al/OPA/PVC laminate blister (Catalent Pharma Solutions, Somerset, NJ, USA) and loaded into an Epsilon 2-6 laboratory scale freeze-dryer (Martin Christ Freeze Dryers, Osterode, Germany). The samples were frozen at the rate of $1 \mathrm{~K} / \mathrm{min}$ to a minimum shelf temperature of $-25^{\circ} \mathrm{C}$ including two equilibration steps at 5 and $-5{ }^{\circ} \mathrm{C}$ for $15 \mathrm{~min}$ to achieve similar nucleation temperatures. After holding samples at $-25^{\circ} \mathrm{C}$ for $1 \mathrm{~h}$, the chamber pressure was decreased to $0.120 \mathrm{mbar}$ and the shelf temperature was increased to $-10{ }^{\circ} \mathrm{C}$ at $1 \mathrm{~K} / \mathrm{min}$ to initiate the main drying. After $6 \mathrm{~h}$ of sublimation, the shelf temperature was further increased to $40{ }^{\circ} \mathrm{C}$ at the rate of $1 \mathrm{~K} / \mathrm{min}$ to initiate the secondary drying. The sublimation phase was carried out over a $5 \mathrm{~h}$ period. Then, samples sealed under vacuum in glass vials were stored at room temperature.

Tablets containing CP loaded IPECs were similarly prepared by weighing the exact amounts of IPEC containing $120 \mu \mathrm{g}$ drug per single unit.

The oral lyophilisates were characterized in terms of uniformity of mass and disintegration time according to the Ph. Eur. 9th edition. After disintegrating one or two tablets in $10 \mathrm{~mL}$ of filtered deionized water (Milli-Q ${ }^{\mathrm{TM}}$ Water system, Millipore Corporation, Vimodrone, Italy), particle size and zeta potential of placebo and loaded IPECs were also measured. 


\subsection{In Vitro Drug Release Test}

The in vitro drug release test was performed according to a "sample-and-separate" method [10]. Considering the limited volumes of fluids in the buccal cavity, the in vitro release test was carried out in oversaturation condition in order to better discriminate the different features of CP loaded IPECs. Oral lyophilisates were placed in closed glass vials containing $20 \mathrm{~mL}$ deionized water and shaken in a horizontal incubator at 50 strokes $/ \mathrm{min}$ and $37 \pm 0.5{ }^{\circ} \mathrm{C}$. At each time point, a volume of $4 \mathrm{~mL}$ medium was diluted with $1 \mathrm{~mL}$ acetonitrile, and the amount of $\mathrm{CP}$ released was quantified by the high-performance liquid chromatography (HPLC) method reported in Section 2.7. The withdrawn medium was replaced with equal volumes of deionized water.

\subsection{HPLC Method}

The CP content loaded into IPECs and released in the in vitro release test was assayed by an HPLC method using HP1100 Chemstation (Agilent Technologies, Cernusco sul Naviglio, Italy). Chromatographic conditions: column: Spherisorb ODS2, $4.6 \mathrm{~mm} \times 150 \mathrm{~mm}, 3 \mu \mathrm{m}$ (Waters, Vimodrone, Italy); mobile phase: $50: 50(\% v / v)$ acetonitrile:water; flow rate: $1.0 \mathrm{~mL} / \mathrm{min}$; wavelength: $240 \mathrm{~nm}$; injection volume: $20 \mu \mathrm{L}$. The drug concentrations were determined from standard curves ranging from 0.1 to $50 \mu \mathrm{g} / \mathrm{mL}[9]$.

\section{Results}

\subsection{Characterization of Placebo IPECs}

All IPECs obtained by mixing EPO and four types of carbomers differing in chemical composition, molecular weight, or cross-linking were insoluble in water. To evaluate the possible interactions between components, a physicochemical study was carried out by MDSC and FTIR spectroscopy. According to the FTIR spectra, a new absorption band at $1560 \mathrm{~cm}^{-1}$ appeared in the IPEC with respect to the raw materials, suggesting the formation of a new chemically individual compound (Figure 1).

This absorption band is diagnostic of the formation of ionic bonds between carboxyl groups of Carbopol ${ }^{\circledR}$ and dimethylamino groups of EPO [16-19] and responsible for complex insolubilization. MDSC data supported the formation of such interaction at a molecular level. EPO and carbomer are both amorphous polymers with a characteristic $T_{\mathrm{g}}$ value (Table 3 ). After IPEC formation, a single value of $T_{\mathrm{g}}$ was detected independently of the nature of anionic polyelectrolytes suggesting the absence of microdomains of free copolymer. Moreover, the shift of $T_{\mathrm{g}}$ towards higher values with respect to the starting polymers, suggests the formation of a stiffer material. The elementary analysis of IPEC after washing revealed the presence of an excess of carbomer polymers in all samples (Table 3).

Regarding the particle size and particle size distribution, C10 and C2020, which provide substantially more viscous solutions than the low molecular weight counterpart, allowed the formation of nanoparticles (Table 4) and aggregates sizing about $5 \mu \mathrm{m}$. The percentage of this population of large particles considerably increased decreasing the EPO content (Table 4). In contrast, the mixing of NAA- 1 and EPO led to the formation of nanoparticles of about $160 \mathrm{~nm}$ with a monomodal distribution (Table 4). 


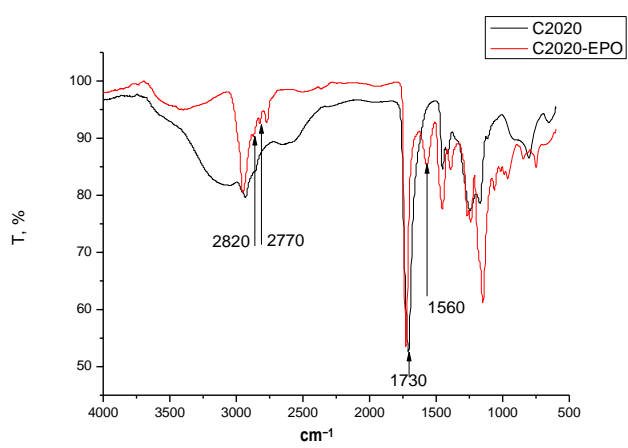

(a)

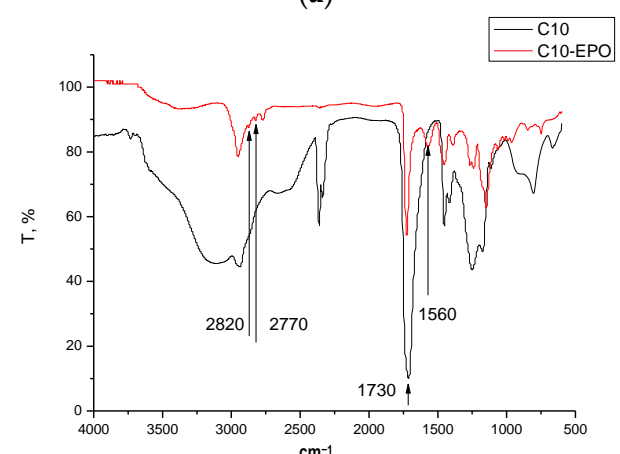

(c)

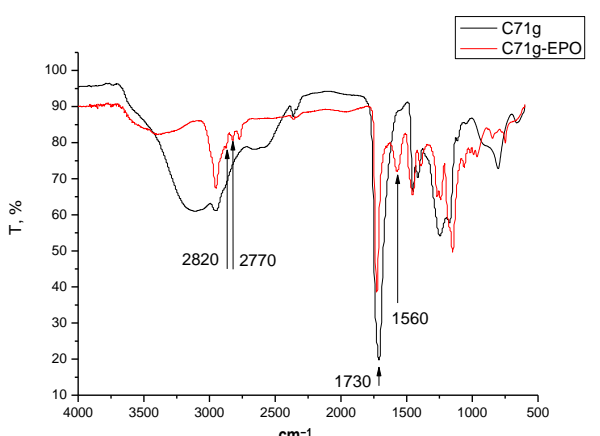

(b)

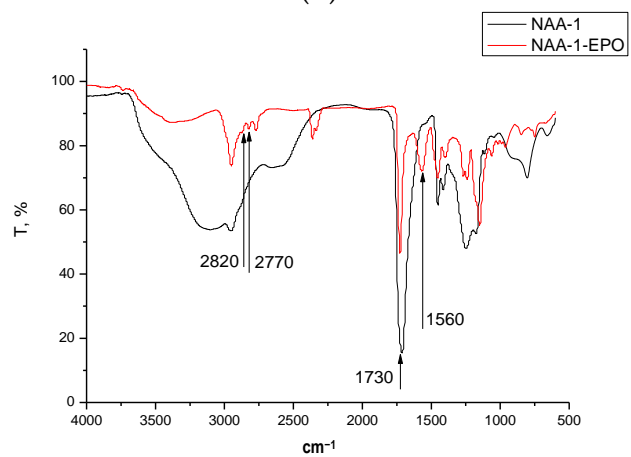

(d)

Figure 1. ATR-FTIR-spectra of C2020 and IPEC C2020/EPO (a); C71G and IPEC C71G/EPO (b); C10 and IPEC C10/EPO (c); and NAA-1 and IPEC NAA-1/EPO (d).

Table 3. MDSC data on raw materials and placebo IPECs.

\begin{tabular}{ccc}
\hline Samples Name & $T_{\mathbf{g}}\left({ }^{\circ} \mathbf{C}\right)$ & Composition $(\mathbf{m o l} / \mathbf{m o l})$ \\
\hline EPO & $52.1 \pm 1.2$ & - \\
C71G & $129.5 \pm 1.2$ & - \\
C2020 & $125.2 \pm 1.2$ & - \\
C10 & $126.5 \pm 1.2$ & - \\
NAA-1 & $131.3 \pm 1.5$ & $2.12: 1^{*}$ \\
C71G/EPO & $132.8 \pm 1.2$ & $1.73: 1^{*}$ \\
C2020/EPO & $133.5 \pm 1.2$ & $2.11: 1^{*}$ \\
C10/EPO & $134.8 \pm 1.1$ & $1.66: 1^{*}$
\end{tabular}

* The composition of carbomer/EPO (mol/mol) IPECs is referred to the elementary analysis.

Table 4. Main physical features, namely hydrodynamic diameter $\left(D_{\mathrm{h}}\right)$, zeta potential $(\zeta)$, and mucoadhesive properties of placebo IPECs. The value in the brackets refers to the percentage of the main population.

\begin{tabular}{|c|c|c|c|c|c|c|c|c|c|}
\hline \multirow{2}{*}{$\begin{array}{l}\text { IPEC } \\
\text { Code }\end{array}$} & \multicolumn{5}{|c|}{ Composition $(\%, w / w)$} & \multirow{2}{*}{$\zeta(\mathrm{mV})$} & \multirow{2}{*}{$D_{\mathrm{h}}(\mathrm{nm})$} & \multirow{2}{*}{$\operatorname{MDF}(\mathbf{k P a})$} & \multirow{2}{*}{ WA (mJ) } \\
\hline & EPO & NAA1 & $\mathrm{C} 10$ & C71G & C2020 & & & & \\
\hline 1 & 67 & 33 & - & - & - & $14.7 \pm 0.5$ & $154 \pm 9(98.0 \%)$ & $111 \pm 10$ & $2611 \pm 413$ \\
\hline 2 & 50 & 50 & - & - & - & $-5.5 \pm 2.5$ & $154 \pm 0(97.6 \%)$ & $100 \pm 13$ & $1848 \pm 335$ \\
\hline 3 & 33 & 67 & - & - & - & $-16.0 \pm 0.4$ & $168 \pm 4(96.1 \%)$ & $49 \pm 6$ & $741 \pm 33$ \\
\hline 4 & 67 & - & 33 & - & - & $7.7 \pm 1.0$ & $222 \pm 9(94.1 \%)$ & $85 \pm 20$ & $1462 \pm 210$ \\
\hline 5 & 50 & - & 50 & - & - & $-5.1 \pm 0.9$ & $158 \pm 4(96.2 \%)$ & $103 \pm 1$ & $2154 \pm 66$ \\
\hline 6 & 33 & - & 67 & - & - & $-13.7 \pm 0.5$ & $149 \pm 13(52.7 \%)$ & $45 \pm 6$ & $643 \pm 57$ \\
\hline 7 & 67 & - & - & 33 & - & $4.3 \pm 1.6$ & $195 \pm 12(63.7 \%)$ & $94 \pm 17$ & $1902 \pm 322$ \\
\hline 8 & 50 & - & - & 50 & - & $-47.8 \pm 2.7$ & $175 \pm 17(97.2 \%)$ & $67 \pm 31$ & $1272 \pm 448$ \\
\hline 9 & 33 & - & - & 67 & - & $-28.8 \pm 1.7$ & $188 \pm 9(96.4 \%)$ & $55 \pm 9$ & $1010 \pm 95$ \\
\hline 10 & 67 & - & - & - & 33 & $-28.2 \pm 4.0$ & $166 \pm 9(90.0 \%)$ & $89 \pm 25$ & $656 \pm 51$ \\
\hline 11 & 50 & - & - & - & 50 & $-28.2 \pm 3.5$ & $192 \pm 11(83.3 \%)$ & $43 \pm 2$ & $678 \pm 25$ \\
\hline 12 & 33 & - & - & - & 67 & $-20.6 \pm 1.8$ & $225 \pm 9(71.9 \%)$ & $57 \pm 5$ & $802 \pm 109$ \\
\hline
\end{tabular}

Chitosan (positive control): $\mathrm{MDF}=62 \pm 10 \mathrm{kPa}$; WA $=1682 \pm 162 \mathrm{~mJ}$. Polyethylene (negative control): $\mathrm{MDF}=13 \pm 1 \mathrm{kPa} ; \mathrm{WA}=407 \pm 175 \mathrm{~mJ}$. 
The evolution of zeta potential as a function of IPEC composition, which can be considered as an indication of the degree of inter-particle interaction, is summarized in Table 4 . As the carbomer concentration increased from $33 \%$ to $67 \%$, the zeta potential values shifted from $15 \mathrm{mV}$ to a negative value according to the extent and the type of anionic copolymer used for the preparation of IPEC. This feature can be attributed to the presence of negatively charged carboxyl groups of Carbopol ${ }^{\circledR}$, which do not participate to the formation of ionic bonds with the positively charged dimethylamino groups of EPO. Moreover, increasing the concentration of polyacrylate within the complex, the number of such carboxylic groups also increases, which give a negative charge to the IPEC particles.

The mucoadhesive properties (in terms of both WA and MDF) of the complexes made with EPO and different types of polyacrylate are reported in Table 4. All the IPEC compositions showed good mucoadhesive properties, since both MDF and WA were statistically higher than those measured using the negative control. As expected, the mucoadhesive performances of IPECs were influenced by the ratio between the polymers. The higher the EPO amount in each IPEC series, the higher the mucoadhesive properties. Indeed, when EPO concentration was $67 \%$, the change of the IPEC charge from negative to positive values, as estimated by the zeta potential, allows the dimethylamino groups of EPO to interact by ionic bonds with the negatively charged ionized groups of sialic acid at the terminus of mucin subunits. The lower values of MDF, associated to a more negative of zeta potential, might be the result of greater repulsion between negative charges of mucin and IPECs.

These results indicate that mucoadhesion of IPECs made of C10, C71G, and NAA-1 are mainly attributed to the formation of electrostatic interactions. On the other hand, such mechanism of interaction cannot help to explain the behaviour of IPEC made with C2020, for which a less negative zeta potential in comparison with the raw polymer (C2020) was related to weaker mucoadhesion. Indeed, beyond the zeta potential values, other features of polymers (e.g., chemical composition and structure) can influence their ability to adhere to mucosa [20]. In the case of raw polymers, the more negative zeta potential may establish a better uncoiling to interpenetrate with oligosaccharide mucin chains. The mucoadhesion of C2020/EPO IPEC can be attributed by the formation of hydrogen bonds between carboxyl groups of Carbopol ${ }^{\circledR}$ and mucin, since mucoadhesion of polymers containing weak anionic carboxyl, such as polyacrylic acid $\left(\mathrm{Carbopol}^{\circledR}\right)$, is often related to the formation of hydrogen bonds with mucin [21].

\subsection{Oral Lyophilisates Containing Placebo IPEC}

The physico-chemical characterization of placebo IPECs permitted to consider two materials worth of further characterization. In particular, C71G/EPO (50:50) and NAA-1/EPO (33:67) were chosen based on the zeta potential value (Table 4) to evaluate how the superficial properties can affect the formulation of oral lyophilisates and resuspendibility. In addition, IPEC made of NAA-1/EPO (33:67) is characterized by the highest rates of mucoadhesion (Table 4), which can also influence the properties of the final dosage form. To obtain oral lyophilisates with suitable characteristics, it is necessary to tune up both the formulation and the lyophilization parameters. Of fundamental importance to preserve IPEC nano-size during the lyophilization process is the selection of the type and concentration of lyoprotectants and steric stabilizers. The "vitrification hypothesis" suggests the possible role of lyoprotectants during freezing: saccharides form a glassy system, known also as cryo-concentrated phase, where nanoparticles are immobilized and preserved from the ice crystals [22]. Besides lyoprotectants, steric stabilizers can improve the nanoparticles stability during the lyophilization according to the "water replacement theory". This theory suggests that the hydrogen bonds between water and nanoparticles are replaced by interactions occurring onto nanoparticles surface with the adsorbed steric stabilizer, thus avoiding particle aggregation or fusion [23]. Steric stabilizers are generally polymers and surfactants, such as polysorbates and poly(vinyl alcohol).

Once both lyoprotectants and steric stabilizers are defined, an adequate lyophilization cycle is designed based on the $T_{\mathrm{g}}{ }^{\prime}$ and the $T \mathrm{c}$. Indeed, the formulation is required to be cooled below its $T_{\mathrm{g}}{ }^{\prime}$ 
to assure the complete solidification [24] and $T \mathrm{c}$, which is the maximum allowable temperature of product during primary drying, to avoid the collapse [25]. Thermal analysis indicated that the $T_{\mathrm{g}}{ }^{\prime}$ of a DS solution at $40 \%$ was $-21.81 \pm 0.3{ }^{\circ} \mathrm{C}$ without being significantly affected by the presence of the surfactant $\left(T_{\mathrm{g}}{ }^{\prime}=-20.56 \pm 0.25^{\circ} \mathrm{C}\right)$; meanwhile the dispersion of $10 \%$ IPEC caused a slight increase in $T_{\mathrm{g}}{ }^{\prime}$ value to $-19.10 \pm 0.04{ }^{\circ} \mathrm{C}$, as exemplified in Figure 2. Hence, the samples were frozen at the temperature of $-25^{\circ} \mathrm{C}$, considering a safety product margin of about $2{ }^{\circ} \mathrm{C}$ [21].

The final concentrations of the additives (i.e., lyoprotectants and steric stabilizers) in the formulations containing IPEC are reported in Table 2. All freeze-dried tablets loaded with IPEC presented as a white spongy texture. The tablets occupied the same volume of the original frozen mass and no shrinkage or cake collapse was observed, demonstrating that the process parameters yielded good lyophilisates.

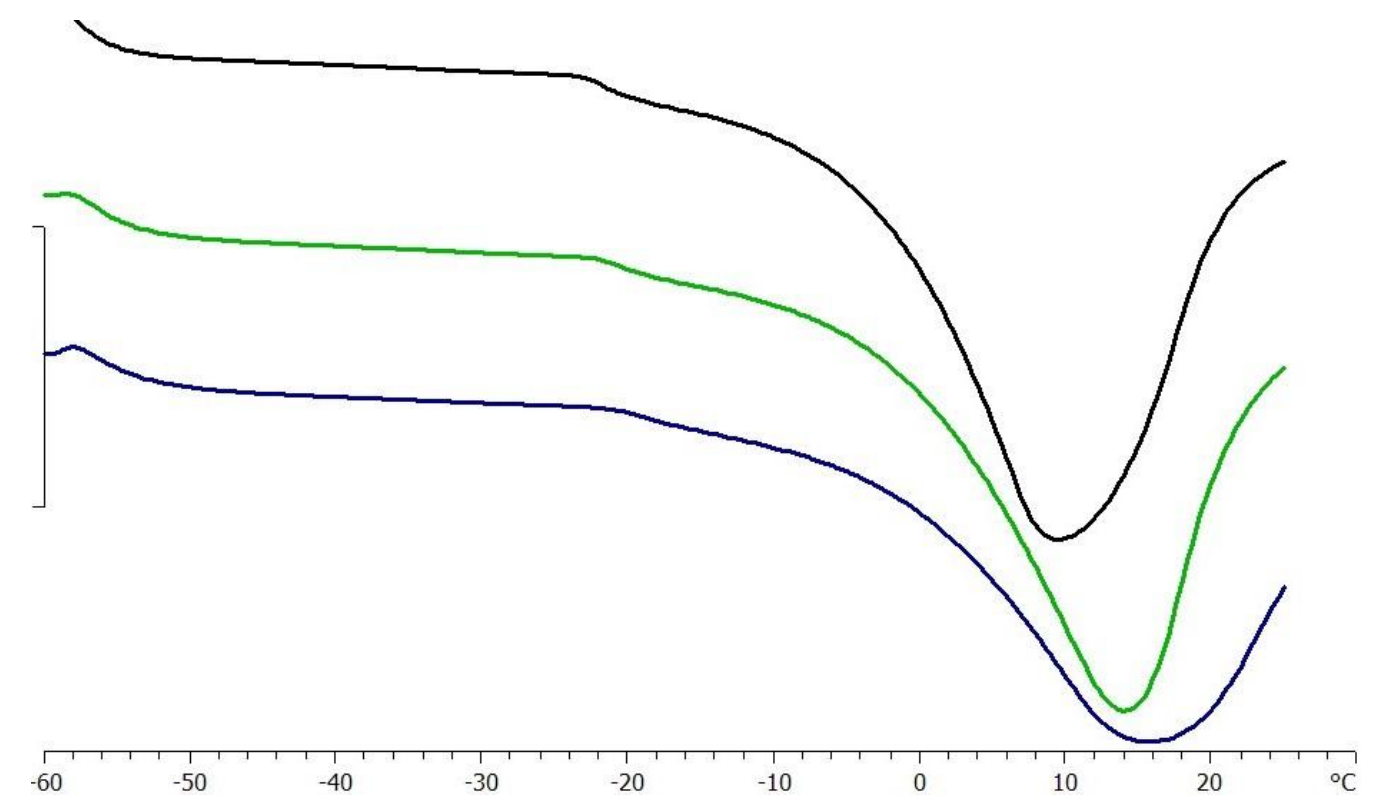

Figure 2. DSC analysis of $40 \%$ solution of DS 38 (black line) in the presence of $0.5 \%$ Span ${ }^{\circledR} 80$ (green line) and 10\% IPEC No.1 (blue line).

Tablets obtained by the DS solution at the highest concentration presented a very irregular surface due to the presence of bubble after filling the blisters. Decreasing the DS concentration to about $40 \%$, visually acceptable tablets were obtained and, therefore, they were disintegrated in water in order to characterize IPECs in terms of particle size and PDI. The presence of a steric stabilizer was essential during lyophilization since DS as such was not able to avoid the formation of large and irreversible aggregates (Table 2). However, sticky tablets, difficult to handle, were obtained by using Tween ${ }^{\circledR} 80$ independently of its concentration and, therefore, discarded from further evaluation. Span ${ }^{\circledR} 80$ was effective as a steric stabilizer as a function of its concentration since only the formulation containing DS in combination with $0.5 \%$ of Span ${ }^{\circledR} 80$ preserved the IPEC size upon lyophilization (Table 2). Additionally, the ratio between the cryoprotectant and IPEC influenced the freeze-drying process, since at 20\% IPEC loading the resuspended particles exhibited a monomodal distribution with a low size heterogeneity (PDI $\sim 0.15$ ). This evidence agreed with the results on the lyopresevation effect of threalose on diblock and triblock poly(lactic acid)-poly(ethylene oxide) copolymer nanoparticles-the lyoprotective efficiency increased at higher nanoparticles concentration [26].

After lyophilization and redispersion, IPECs shifted their characteristic surface charge from about 15 to $-25 \mathrm{mV}$ (Table 2). This variation can be the result of a "masking-effect" due to the adsorption of maltodextrin on the positive surface of IPEC. This result is in line with literature data since the 
entrapment of nanoparticles in some polymers usually modifies the zeta potential because the coating layers shield the surface charge and move the shear plane out wards from the particle surface [27-29].

According to the obtained results, the optimal composition was 20\%, IPEC NAA-1/EPO (33:67), $40.9 \%$ DS, and $0.5 \%$ Span ${ }^{\circledR} 80$ since the resulting oral lyophilisates have the required disintegration time ( $<30 \mathrm{~s})$ and after disintegration test IPEC particles had a monomodal distribution without aggregates. Thus, this composition was selected to produce oral lyophilisates loaded with CP.

\subsection{CP Loaded IPECS}

The effect of different CP loading on the main features of IPEC made of NAA- 1 and EPO in the ratio 33:67 was evaluated. The loading procedure gave a high encapsulation efficiency in all considered ratios (Table 5).

Table 5. Characterization of clobetasol propionate (CP) loaded into IPEC formed by NAA-1 and EPO in the ratio $33: 67 \%$.

\begin{tabular}{ccccccc}
\hline \multirow{2}{*}{ Composition } & \multicolumn{2}{c}{ CP Content $\mathbf{( \% )}$} & \multirow{2}{*}{$\boldsymbol{D}_{\mathbf{h}}(\mathbf{n m})$} & $\boldsymbol{\zeta}(\mathbf{m V})$ & \multirow{2}{*}{ MDF (kPa) } & \multirow{2}{*}{ WA (mJ) } \\
\cline { 2 - 3 } & Theoretic & Actual & & & & \\
\hline CP-IPEC 50:50 & 50 & $53.2 \pm 0.3$ & $401 \pm 295$ & $-11.3 \pm 2.1$ & $30 \pm 6$ & $2530 \pm 58$ \\
CP-IPEC 60:40 & 60 & $56.1 \pm 1.4$ & $435 \pm 197$ & $-9.0 \pm 1.2$ & $22 \pm 5$ & $2988 \pm 110$ \\
CP-IPEC 70:30 & 70 & $62.1 \pm 5.3$ & $431 \pm 119$ & $-10.8 \pm 1.2$ & $18 \pm 2$ & $2550 \pm 27$ \\
CP-IPEC 80:20 & 80 & $79.4 \pm 0.2$ & $560 \pm 116$ & $6.8 \pm 2.8$ & $16 \pm 2$ & $1400 \pm 26$ \\
CP-IPEC 90:10 & 90 & $88.5 \pm 12.6$ & $416 \pm 6$ & $3.8 \pm 2.2$ & $15 \pm 1$ & $820 \pm 19$ \\
\hline
\end{tabular}

The FTIR spectra of CP loaded IPECs revealed that no interactions occurred independently on their ratio (Figure 3).

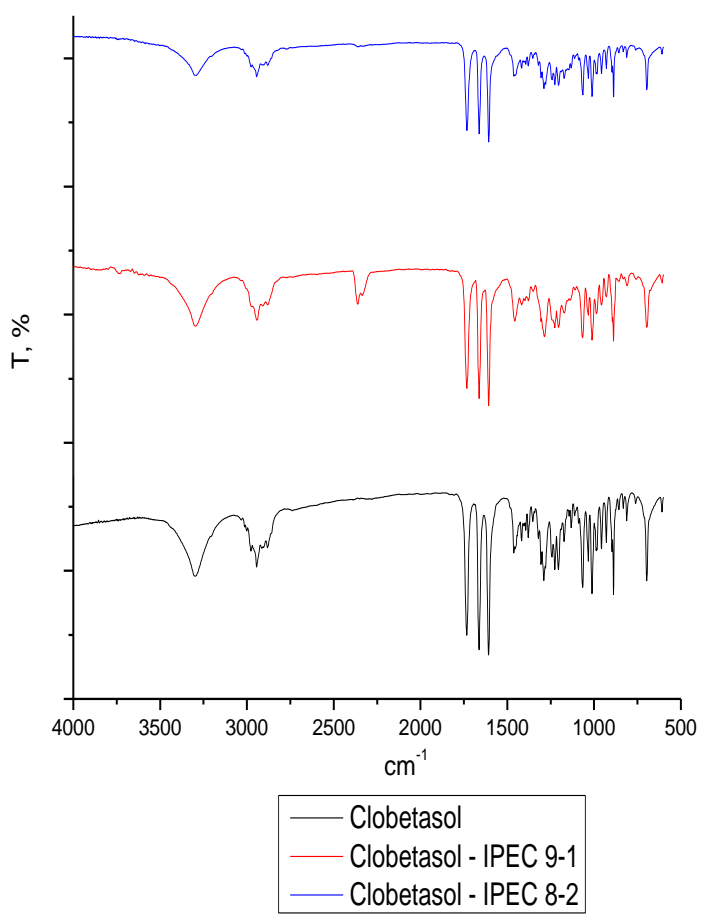

(a)

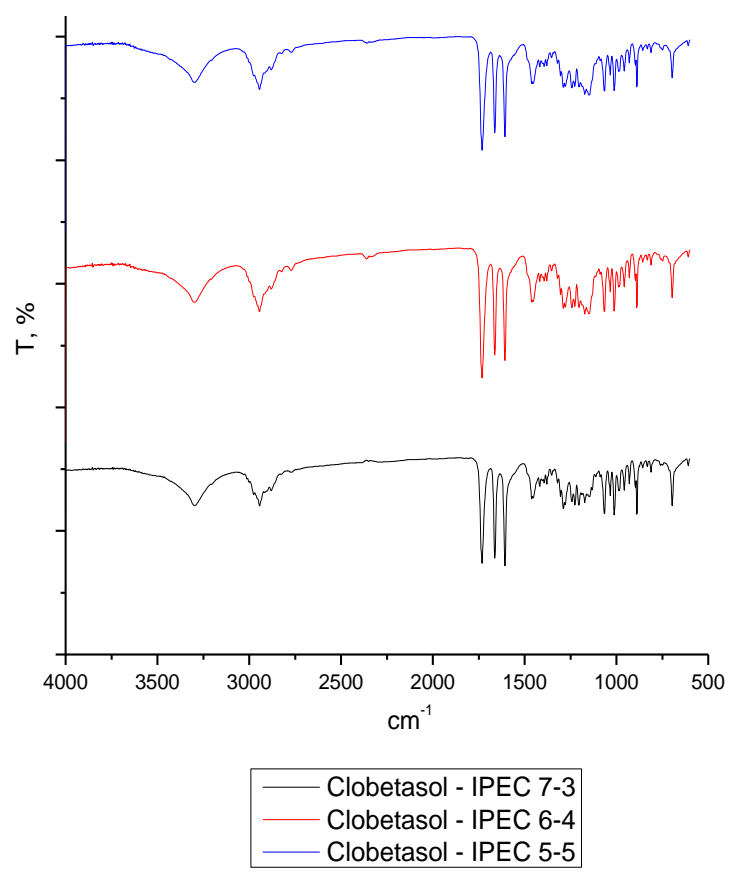

(b)

Figure 3. ATR-FTIR-spectra of raw material CP (panel (a)) and CP loaded IPECs in the following ratio: (panel (a)) 9:1, 8:2; (panel (b)) 7:3, 6:4, 5:5. 
This result is consistent with the MDSC data as the endothermic event attributed to CP melting was observed in all samples and it increased the drug content accordingly (Figure 4). Independently of the drug content, IPEC dimension increased from around 160 to $450 \mathrm{~nm}$ (Table 5). This behavior can be due to the presence of aggregates since the drug loading caused a shift of zeta potential value in the range of instability (Table 5).

As far as the mucoadhesion is concerned, the drug loading led to a decrease in the MDF values of IPECs (Table 5), at a higher extent with increasing CP content. As a matter of fact, the values obtained for CP content higher than 70\% (i.e., formulations CP-IPEC 80:20 and 90:10) resulted not significantly different from the negative control. On the other hand, for all the tested formulations, WA was higher than the negative control and, for those with low CP content (i.e., formulations CP-IPEC 50:50, 60:40, and 70:30), it was of the same order of magnitude of the corresponding placebo IPECs.

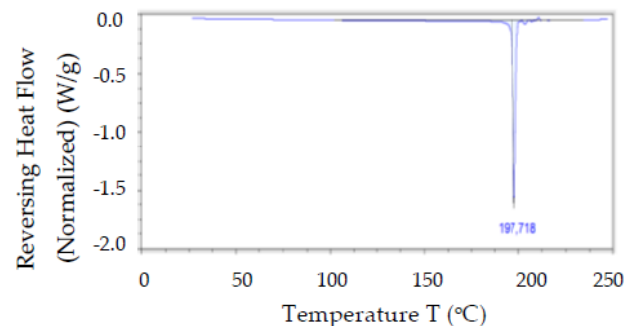

(a)

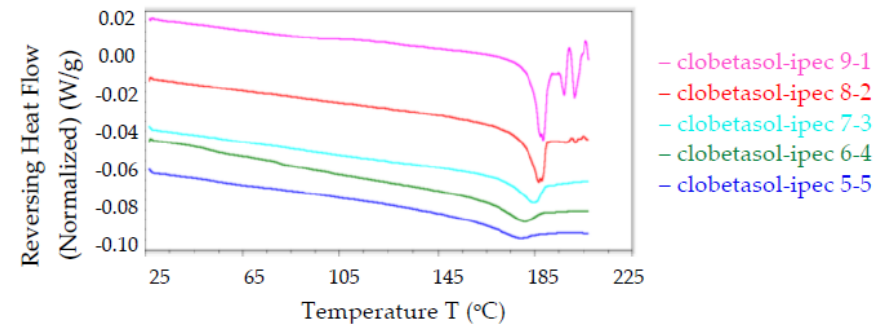

(b)

Figure 4. MDSC thermograms of (a) CP raw material and (b) CP loaded CP-in different ratios, namely 90:10, 80:20, 70:30, 60:40, and 50:50.

In the case of drug loaded IPECs, the decrease in MDF, not concurrent with a decrease in WA, could be due to an increase of the viscous modulus of the hydrated interpolymeric complex/mucin mixture. As a matter of fact, the last phase during the separation of the drug loaded IPECs showed a resistance to the detachment in terms of elongation and time, higher than the placebo. Indeed, the mucin compact was not totally detached from IPEC compact due to the formation of visually observed fibrils. Oral lyophilisates were obtained by dispersing an appropriate amount of CP loaded IPECs in the DS solution in order to have a drug content of $120 \mu \mathrm{g} / \mathrm{unit}$. The final composition is reported in Table 6. After freeze-drying all tablets appeared as elegant solids without defects or sign of collapse, easy to remove from blister and to handle. The disintegration time of all oral lyophilisates was less than $30 \mathrm{~s}$ and no aggregates were detected confirming suitability of components to stabilize IPECs during the lyophilization process (Table 6). The zeta potential values of all resuspended IPECs shifted towards the neutrality probably because the excipients remained adsorbed on the IPEC surface.

Table 6. Composition of oral lyophilisates containing CP loaded IPECs formed by NAA-1 and EPO in the ratio 33:67\%. The amount of IPEC was defined in order to have $120 \mu \mathrm{g}$ drug per unit. The main features of CP loaded IPECs after disintegration were evaluated in terms of particle size $\left(D_{\mathrm{h}}\right)$ and zeta-potential ( $\zeta$ ).

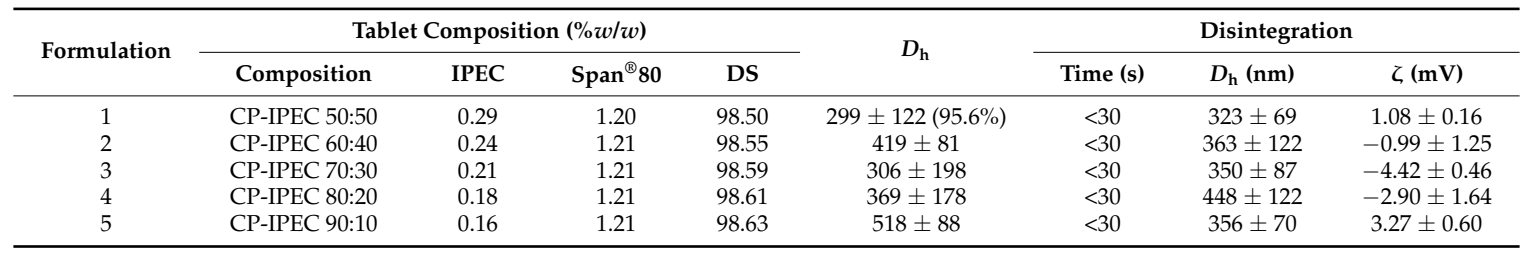

The dissolution profiles showed that the CP encapsulation into IPEC improved its apparent solubility as a function of the loaded drug amount (Figure 5). Indeed, the CP-IPEC ratio of 50:50 exhibited the highest supersaturation degree, which was conversely unstable, since after $120 \mathrm{~min}$ the 
concentration of $\mathrm{CP}$ in the dissolution medium was superimposable to that of $\mathrm{CP}$ solubility. On the other hand, at the CP-IPEC ratio of 90:10 (Formulation 5) the steady state was reached in about $2 \mathrm{~h}$. Based on these observations, it can be assumed that IPEC not only controlled the drug release rate, but also favored the stabilization of the supersaturated system. Indeed, when the $\mathrm{CP}$ amount ranged from $80 \%$ to $60 \%$ (Formulations 2-4, Table 6), a stable supersatured solution was obtained over the entire considered period of time.

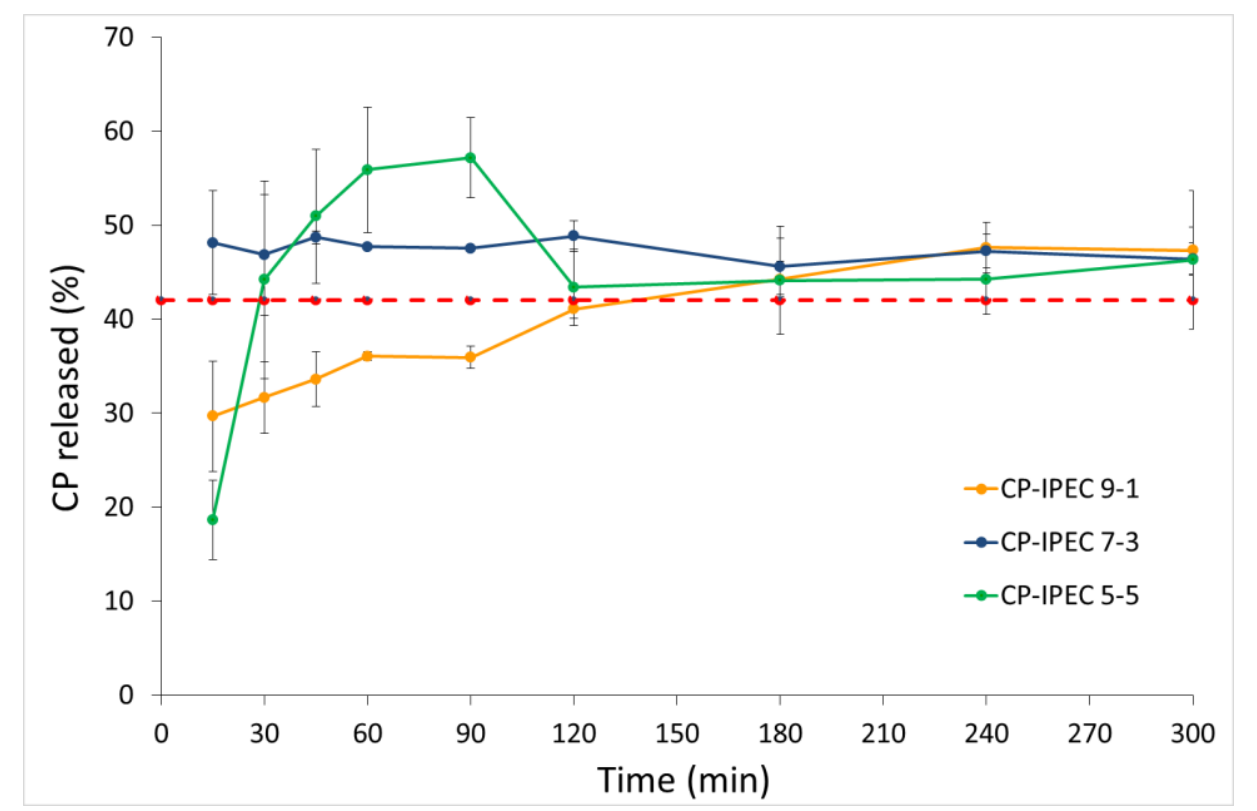

Figure 5. In vitro dissolution profile of CP from oral lyophilisates containing CP-IPEC $w / w$ : 9:1 (90:10), 7:3 (70:30), and 5:5 (50:50) under oversaturation conditions. The dotted line corresponds to the CP solubility at the saturation.

\section{Conclusions}

A new drug delivery system obtained combining the colloidal and mucoadhesive properties of IPEC formed by Carbopol ${ }^{\circledR}$ and EPO, was proposed to treat buccal pathologies. In particular, the ability to interact with mucin was attributed to the IPEC structural features, namely the presence of free dimethylamino groups of EPO or carboxylate groups of Carbopol ${ }^{\circledR}$. Indeed, the higher the mucoadhesion, the higher the excess of unbalanced charge in IPEC. Regarding oral lyophilisates, the use of maltodextrin DE 38 and Span ${ }^{\circledR} 80$ preserved the IPEC size during the thermal stress so that it was possible to reconstitute the original nanosuspension upon contact with water in few seconds. Moreover, this approach allowed to improve the CP apparent solubility thanks to the formation of a stable supersaturated system.

Hence, the overall data suggest that this dosage form could be advantageously exploited in drug delivery systems as demonstrated in the case of clobetasol propionate.

The performed work also permitted us to withdraw general information on the design of oral lyophilisates loaded with nanosized particles. Scheme 1 detained the general approach, underling the selection criteria of each phase and the most important variables to be considered.

Acknowledgments: This work was carried out in the framework of the activities of the Cooperation Agreement stipulated between the Kazan State Medical University and the University of Milan, 2014-2019. It is partially supported by the Russian Foundation for Basic Research via grant 16-04-01692 (to Venera R. Garipova and Rouslan I. Moustafine).

Author Contributions: Rouslan I. Moustafine and Francesco Cilurzo conceived and designed the experiments; Venera R. Garipova, Chiara G. M. Gennari, and Francesca Selmin carried out the experiments; all authors analyzed the data and wrote the paper. 
Conflicts of Interest: The authors declare no conflict of interest.

\section{References}

1. Bourganis, V.; Karamanidou, T.; Kammona, O.; Kiparissides, C. Polyelectrolyte complexes as prospective carriers for the oral delivery of protein therapeutics. Eur. J. Pharm. Biopharm. 2017, 111, 44-60. [CrossRef] [PubMed]

2. Alfurhood, J.A.; Sun, H.; Kabb, C.P.; Tucker, B.S.; Matthews, J.H.; Luesch, H.; Sumerlin, B.S. Poly(N-(2-hydroxypropyl)methacrylamide)-valproic acid conjugates as block copolymer nanocarriers. Polym. Chem. 2017, 8, 4983-4987. [CrossRef] [PubMed]

3. Dillen, K.; Vandervoort, J.; Van den Mooter, G.; Ludwig, A. Evaluation of ciprofloxacin-loaded Eudragit ${ }^{\circledR}$ RS100 or RL100/PLGA nanoparticles. Int. J. Pharm. 2006, 314, 72-82. [CrossRef] [PubMed]

4. Luppi, B.; Bigucci, F.; Mercolini, L.; Musenga, A.; Sorrenti, M.; Catenacci, L.; Zecchi, V. Novel mucoadhesive nasal inserts based on chitosan/hyaluronate polyelectrolyte complexes for peptide and protein delivery. J. Pharm. Pharmacol. 2009, 61, 151-157. [CrossRef] [PubMed]

5. Mustafin, R.I. Interpolymer combinations of chemically complementary grades of Eudragit copolymers: A new direction in the design of peroral solid dosage forms of drug delivery systems with controlled release. Pharm. Chem. J. 2011, 45, 285-295. [CrossRef]

6. Kramarenko, E.Y.; Khokhlov, A.R.; Reineker, P. Stoichiometric polyelectrolyte complexes of ionic block copolymers and oppositely charged polyions. J. Chem. Phys. 2006, 125, 194902. [CrossRef] [PubMed]

7. Hartig, M.S.; Greene, R.R.; Dikov, M.M.; Prokop, A.; Davidson, J.M. Multifunctional nanoparticulate polyelectrolyte complexes. Pharm. Res. 2007, 24, 2353-2369. [CrossRef] [PubMed]

8. Mustafin (Moustafine), R.I.; Semina, I.I.; Garipova, V.A.; Bukhovets, A.V.; Sitenkov, Y.A.; Salakhova, A.R.; Gennari, C.G.M.; Cilurzo, F. Comparative study of polycomplexes based on Carbopol ${ }^{\circledR}$ and oppositely charged polyelectrolytes as a new oral drug delivery system. Pharm. Chem. J. 2015, 49, 1-6. [CrossRef]

9. Cilurzo, F.; Musazzi, U.M.; Franzè, S.; Selmin, F.; Minghetti, P. Orodispersible dosage forms: Biopharmaceutical improvements and regulatory requirements. Drug Discov. Today 2017. [CrossRef] [PubMed]

10. Cilurzo, F.; Gennari, C.G.M.; Selmin, F.; Epstein, J.B.; Gaeta, G.M.; Colella, G.; Minghetti, P. A new mucoadhesive dosage form for the management of oral lichen planus: Formulation and clinical study. Eur. J. Pharm. Biopharm. 2010, 76, 437-442. [CrossRef] [PubMed]

11. Guidelines for the Management of Oral Lichen Planus in Secondary Care-October 2010. Available online: www.bsom.org.uk/LP_guidelines_-_BSOM.pdf (accessed on 14 January 2018).

12. Selmin, F.; Franceschini, I.; Cupone, I.E.; Minghetti, P.; Cilurzo, F. Aminoacids as non-traditional plasticizers of maltodextrins fast-dissolving films. Carbohyd. Pol. 2015, 115, 613-616. [CrossRef] [PubMed]

13. Herbig, M.E.; Evers, D.H. Correlation of hydrotropic solubilization by urea with $\log$ D of drug molecules and utilization of this effect for topical formulations. Eur. J. Pharm. Biopharm. 2013, 85, 158-160. [CrossRef] [PubMed]

14. Cilurzo, F.; Minghetti, P.; Selmin, F.; Casiraghi, A.; Montanari, L. Polymethacrylate salts as new low-swellable mucoadhesive materials. J. Control. Release 2003, 88, 43-53. [CrossRef]

15. Jabbari, E.; Wisniewski, N.; Peppas, N.A. Evidence of mucoadhesion by chain interpenetration at a poly(acrylic acid)/mucin interface using ATR-FTIR spectroscopy. J. Control. Release 1993, 26, 99-108. [CrossRef]

16. Mustafin, R.I.; Kabanova, T.V.; Zhdanova, E.R.; Bukhovets, A.V.; Garipova, V.A.; Nasibullin, S.F.; Kemenova, V.A. Synthesis and physicochemical evaluation of new carrier based on interpolyelecrtolyte complex formed by Eudragit ${ }^{\circledR}$ EPO and Carbomer 940. Pharm. Chem. J. 2010, 44, 271-273. [CrossRef]

17. Mustafin, R.I.; Kabanova, T.V.; Semina, I.I.; Bukhovets, A.V.; Garipova, V.A.; Shilovskaya, E.V.; Nasibullin, S.F.; Sitenkov, A.Y.; Kazakova, R.R.; Kemenova, V.A. Biopharmaceutical assessment of a polycomplex matrix system based on Carbomer 940 and Eudragit ${ }^{\circledR}$ EPO for colon-specific drug delivery. Pharm. Chem. J. 2011, 45, 491-494. [CrossRef]

18. Mustafin, R.I.; Kabanova, T.V.; Zhdanova, E.R.; Bukhovets, A.V.; Garipova, V.A.; Nasibullin, S.F.; Kemenova, V.A. Diffusion-transport properties of a polycomplex matrix system based on Eudragit ${ }^{\circledR}$ EPO and Carbomer 940. Pharm. Chem. J. 2010, 44, 147-150. [CrossRef] 
19. Moustafine, R.I.; Kabanova, T.V.; Kemenova, V.A.; Van den Mooter, G. Characteristics of interpolyelectrolyte complexes of Eudragit E 100 with Eudragit L 100. J. Control. Release 2005, 103, 191-198. [CrossRef] [PubMed]

20. Russo, E.; Selmin, F.; Baldassari, S.; Gennari, C.G.M.; Caviglioli, G.; Cilurzo, F.; Minghetti, P.; Parodi, B. A focus on mucoadhesive polymers and their application in buccal dosage forms. J. Drug Deliv. Sci. Technol. 2016, 32, 113-125. [CrossRef]

21. Albarkah, Y.; Green, R.J.; Khutoryanskiy, V.V. Probing the mucoadhesive interactions between porcine gastric mucin and some water-soluble polymers. Macromol. Biosci. 2015, 15, 1546-1553. [CrossRef] [PubMed]

22. Levine, H.; Slade, L. Another view of trehalose for drying and stabilizing biological materials. Eur. J. Pharm. Biopharm. 1992, 5, 36-40.

23. Crowe, J.H.; Crowe, L.M.; Carpenter, J.F. Preserving dry biomaterials: The water replacement hypothesis. Eur. J. Pharm. Biopharm. 1993, 6, 28-37.

24. Tang, X.; Pikal, M. Design of freeze-drying processes for pharmaceuticals: Practical advice. Pharm Res. 2004, 21, 191-200. [CrossRef] [PubMed]

25. Pikal, M.J.; Shah, S.; Roy, M.L.; Putman, R. The secondary drying stage of freeze drying: Drying kinetics as a function of temperature and chamber pressure. Int. J. Pharm. 1990, 60, 203-207. [CrossRef]

26. De Jaeghere, F.; Allémann, E.; Feijen, J.; Kissel, T.; Doelker, E.; Gurny, R. Freeze-drying and lyopreservation of diblock and triblock poly (lactic acid)-poly (ethylene oxide)(PLA-PEO) copolymer nanoparticles. Pharm. Dev. Technol. 2000, 5, 473-483. [CrossRef] [PubMed]

27. Hawley, A.E.; Illum, L.; Davis, S.S. Preparation of biodegradable, surface engineered PLGA nanospheres with enhanced lymphatic drainage and lymph node uptake. Pharm. Res. 1997, 14, 657-661. [CrossRef] [PubMed]

28. Tobio, M.; Gref, R.; Sanchez, A.; Langer, R.; Alonso, M.J. Stealth PLA-PEG nanoparticles as protein carriers for nasal administration. Pharm. Res. 1998, 15, 270-275. [CrossRef] [PubMed]

29. Redhead, H.M.; Davis, S.S.; Illum, L. Drug delivery in poly (lactide-co-glycolide) nanoparticles surface modified with poloxamer 407 and poloxamine 908: In Vitro characterization and in vivo evaluation. J. Control. Release 2001, 70, 353-363. [CrossRef] 